\title{
COGNITIVE DEVELOPMENT OF CHILDREN WITH LEARNING
}

\section{DISABILITIES: AN INTERVENTION STUDY}

\author{
SIVVALA RADHIKA ${ }^{1} \&$ V. KAVITHA KIRAN ${ }^{2}$ \\ ${ }^{1}$ Research Scholar, Department of Psychology, Osmania University, Hyderabad, India \\ ${ }^{2}$ Home science, Department of Human development and Family studies, College of Home science Hyderabad, India
}

\begin{abstract}
The aim of the study was to ascertain the impact of cognitive intervention on general mental abilities of learning disabled children. Sample for the study consisted 80 experimental and 80 control groups learning disabled children from grade 3. The experimental group children were given cognitive intervention for a period of 10 months. The pre post test indicates that the intervention had a significant impact in improving the mental abilities of children.

KEYWORDS: the impact of cognitive intervention on general mental abilities, improving the mental abilities of children
\end{abstract}

Received: May 21, 2017; Accepted: Jun 10, 2017; Published: Jul 20, 2017; Paper Id.: IJESRAUG20177

\section{INTRODUCTION}

Learning disabled students demonstrate difficulty with cognitive processing that negatively influences their reading and mathematical performance. Cognitive development is the construction of thought processes, including remembering, problem solving, and decision-making, from childhood through adolescence to adulthood. Among the areas of cognitive development are information processing, intelligence, reasoning, language development, and memory. Cognitive approaches, help children become aware of implicit rules by making them explicit, asking the child questions to prompt them to see and understand the link between one event and another. The major difference between various cognitive approaches is simply the way in which the strategies are taught. In most instances, however, strategies are introduced in the context of the child's environment, using tasks that the child needs, or wants, to do. When a child uses a strategy that is introduced by a therapist, it initially serves a compensatory purpose. Through practice and improved metacognitive knowledge, the strategy becomes internalized and the child becomes able to regulate his or her behavior and task performance more effectively (Vygotsky, 1978).

Objective: The objective of the present study is to ascertain the impact of cognitive intervention on the mental abilities of learning disabled children

\section{METHODOLOGY}

\section{Sampling Procedure}

A sample of 160 academically low achieving students studying in the grade 3 were selected from Four large Government Primary Schools belonging of Hyderabad. Students in the age range of 8-10 years from schools that were offering English Medium along with state syllabus were selected. From 160 children 80 formed the experimental group and 80 control groups.

Tool: General Mental Ability Test to assess cognitive development. This test was developed by Sri Vatsava 
R.P. and Saxsena.K (2005) for children in the age range of 7-11 years. This test examines the classification, seriation \& differentiation, reasoning and problem solving cognitive abilities of children.

\section{Intervention}

Intervention program was planned for the period of 10 months for the Learning Disabled students. Material required for the intervention was prepared with the help of "Educating children with learning problems in primary schools" Resource Book for teachers developed by the Research staff of National institute for the Mentally Handicapped. Experimental group I i.e the reading disability group consists of 40 children with reading disabilities and experimental group II consists of 40 children with math disabilities. The selected subjects belong to both the reading and maths, Experimental groups. They were given remedial intervention to upgrade their learning skills while the other two groups of 40 subjects in each group, i.e. Reading disability control group and math disability control group, who were not given any kind of intervention. A pre post intervention design was used for the study. Subjects from experimental groups I i.e Reading disability group were exposed to phonic training and cognitive strategy training using visualizing, segmenting, sequencing, prompting, rehearsal and cueing. Subjects from experimental group II having dyscalculia or mathematical disabilities were taught basic mathematical concepts using cognitive strategies. Data was analyzed by comparing the Experimental and control groups to note the improvement in learning due to intervention.

\section{RESULTS AND DISCUSSIONS}

The tables presented in this section discuss General mental ability test scores obtained for the selected sample that are reading and mathematics disability Groups for pre, mid and post intervention. The table below shows pre, mid and post intervention scores, their SDs, f ratios and their $\mathrm{p}$ values.

Table 1: Showing Pre, Mid and Post Test Mean, S.Ds and 'F' Test of Reading and Maths for the Experimental and Control Groups on General Mental Abilities Test

\begin{tabular}{|c|c|c|c|c|c|c|c|c|c|c|c|c|}
\hline \multirow{3}{*}{ Analysis } & \multicolumn{6}{|c|}{ Reading } & \multicolumn{6}{|c|}{ Mathematics } \\
\hline & \multicolumn{3}{|c|}{$\begin{array}{l}\text { Experimental Group } \\
\text { (R) }\end{array}$} & \multicolumn{3}{|c|}{ Control Group (R) } & \multicolumn{3}{|c|}{$\begin{array}{c}\text { Experimental Group } \\
\text { (M) }\end{array}$} & \multicolumn{3}{|c|}{ Control Group (M) } \\
\hline & Pre & Mid & Post & Pre & Mid & Post & Pre & Mid & Post & Pre & Mid & Post \\
\hline Mean & 15.56 & 20.28 & 27.83 & 15.43 & 16.07 & 16.82 & 16.01 & 20.13 & 25.56 & 15.11 & 15.61 & 16.58 \\
\hline SD & 4.59 & 5.22 & 5.79 & 4.40 & 4.43 & 4.44 & 4.15 & 4.44 & 5.40 & 3.94 & 3.52 & 3.444 \\
\hline f ratio & \multicolumn{3}{|c|}{56.733} & \multicolumn{3}{|c|}{0.99} & \multicolumn{3}{|c|}{41.65} & \multicolumn{3}{|c|}{1.687} \\
\hline $\mathrm{p}$ value & \multicolumn{3}{|c|}{$0.00 * *$} & \multicolumn{3}{|c|}{0.375} & \multicolumn{3}{|c|}{$0.00 * *$} & \multicolumn{3}{|c|}{$0.190 \mathrm{NS}$} \\
\hline
\end{tabular}

$* * \mathrm{p}<0.01$ level of significance $\quad$ NS - Not significant

The above table shows differences in reading and mathematics, experimental and control group students for the pre, mid and post intervention tests. The pre test mean score of the Reading Experimental group was found to be 15.56 and SD 4.59. In the Mid intervention the mean score was found to be 20.28 whereas in the case of post test it was found to be 27.83. This shows that there is a consistent increase from pre to mid to post test scores of the intervention for the reading experimental group subjects. There is a definite increase from pre test to post test scores after the intervention showing that the intervention had a positive effect on the Reading Experimental group. The differences in means from pre-mid and mid to post test scores were found to be highly significant $(F=56.7, p<0,01)$ whereas the scores for the Control group $R$ almost remained same in pre, mid and post test, hence no significant differences were found between these scores, which means that there is improvement only for the reading experimental group. 
In case of intervention for mathematics group the pre test mean of the experimental group was 16.01 and SD 4.15. The results of midterm intervention showed a mean score of 20.13 and SD 4.44. The post test scores were found to be high $($ mean=25.56 and SD = 5.4). The 'F' value calculated between pre-mid and post test scores showed a highly significant difference from pre-mid to post stage of intervention for Experimental group $\mathrm{M}(\mathrm{F}=41.65, \mathrm{p}<0.01)$. This indicates that there has been a consistent increase in learning from pre-mid -post due to the effect of intervention being given.

The results of mathematical control group suggest that there was no significant improvement in the scores from pre- mid to post intervention $(\mathrm{F}=1.68, \mathrm{p}>0.05)$. This indicates that the control group showed no significant change with its test scores as no intervention was given to them.

There was a negligible difference in the scores of both the Reading control group and the Math control group. But it can be seen from the results of both Reading and Math experimental Groups that there was a significant increase in performance from pre to post test due to the intervention being effective.

Hence it can be stated that this finding satisfying the objective -3 i.e., To study the effect of intervention on cognitive development of children with learning disabilities.

This finding supports the findings of the study done by Ceci \& Stephen, J. (1991) who revealed after their study that increased exposure to geometric figures, patterns and pictorial information to students contribute to rising mean Intelligent Quotient (IQ).

Table 2: Showing Pre, Mid and Post Intervention Means, SDs and T Values for the Experimental (Reading) and Control Group on General Mental Ability -Verbal Scale

\begin{tabular}{|c|c|c|c|c|c|}
\hline Group & Pre/Post & Mean & SD & T value & P value \\
\hline Experimental (R) & \multirow{2}{*}{ Pre } & 13.1 & 5.19 & \multirow{2}{*}{1.6259} & \multirow{2}{*}{0.108} \\
\hline Control group ( $\mathbf{R})$ & & 14.9 & 4.7 & & \\
\hline Experimental (R) & \multirow{2}{*}{ Mid } & 17.97 & 5.19 & \multirow{2}{*}{2.1673} & \multirow{2}{*}{$0.053 *$} \\
\hline Control group $(\mathbf{R})$ & & 15.55 & 4.8 & & \\
\hline Experimental group (R) & \multirow{2}{*}{ Post } & 24.98 & 5.13 & \multirow{2}{*}{10.75} & \multirow{2}{*}{$0.0001 * *$} \\
\hline Control group $(\mathbf{R})$ & & 17.17 & 3.72 & & \\
\hline
\end{tabular}

$* \mathrm{p}<0.05$ level of significance, $* * 0.01$ level of significance

$\mathrm{R}=$ Reading disability group

The above table shows comparisons of means, SDs and ' $\mathrm{t}$ ' values of the Reading disability scores for pre, mid and post intervention scores. It can be seen from the above table that the pre test mean score of Experimental group were mean $=13.1, \mathrm{SD}=5.19$ whereas the control group mean $=14.0$ and $\mathrm{SD}=4.7$. In the pre test ' $\mathrm{t}$ ' value between the experimental and control group was 1.625 which was found to be insignificant. In case of the mid test results, experimental Group means=17.97 and $\mathrm{SD}=5.19$ where as for the control group $(\mathrm{R})$ scores were mean=15.55 and $\mathrm{SD}=4.8$. The calculated $\mathrm{t}$ value between the experimental and control group for mid test was found to be $t=2.16<0.05$. The post test results showed the mean score of experimental $\mathrm{R}$ (mean=24.98 and $\mathrm{SD}=5.13$ ) and control $\mathrm{R}(\mathrm{Mean}=17.17$ and $\mathrm{SD}=3.72)$ showed a highly significant difference with $\mathrm{t}$ value $=10.75$ and $\mathrm{p}<0.01$

Hence it was evident from the results that maximum effect of intervention could be seen in the post test with $t$ value highly significant.

These findings confirm the results of the study done by Klingberg, T., Forssberg, H., \& Westerberg, H., (2002) who found that children with attention deficit disorder who received a cognitive skills training program obtained high IQ 
scores on Raven's test when compared to control group children.

Table 3: Shows Pre, Mid and Post Intervention Means, SDs T Values after the Intervention of the Experimental (Math)and Control Group on General Mental Ability -Verbal Scale

\begin{tabular}{|c|c|c|c|c|c|}
\hline Group & Pre/Post & Mean & SD & T Test & P value \\
\hline Experimental (M) & \multirow{2}{*}{ Pre } & 16 & 3.73 & \multirow{2}{*}{0.94} & \multirow{2}{*}{0.34} \\
\hline Control group (M) & & 15.2 & 3.86 & & \\
\hline Experimental (M) & \multirow{2}{*}{ Mid } & 20.05 & 5.06 & \multirow{2}{*}{4.68} & \multirow{2}{*}{$0.05^{*}$} \\
\hline Control group $(\mathrm{M})$ & & 15.5 & 3.66 & & \\
\hline Experimental group $(\mathrm{M})$ & \multirow{2}{*}{ Post } & 25.2 & 4.21 & \multirow{2}{*}{10.21} & \multirow{2}{*}{$0.0001 * *$} \\
\hline Control group $(\mathrm{M})$ & & 16.72 & 3.14 & & \\
\hline
\end{tabular}

The findings of the table 3 indicate that in pre intervention condition the mean of the maths experimental group on a verbal scale of mental ability was 16 and SD 3.73 whereas the pre test mean of the control group is 15.2 (S.D 3.8 ). The $t$ value obtained between the experimental and control group during the pre test was $0.94, \mathrm{p}<0.05$ indicating no significant difference between the two groups. In the mid intervention the mean score of the experimental group was found to be $20.05 \& \mathrm{SD}=5.06$ and for the control group mean was 15.5 with SD 3.66. The t value of 4.68 and $\mathrm{p}<0.05$ level between the experimental and control group indicates a significant difference in mid test mean scores. However, in post test the mean of the experimental group was found to be 25.2 and $\mathrm{SD}=4.21$ while the control group mean was 16.72 with $3.14 \mathrm{SD}$. When the men of both groups was compared with t test a highly significant difference was found with t' value 10.2 and $\mathrm{p}<0.01$. The results indicated that the effectiveness of cognitive intervention for Math disabled students in improving their scores on general mental ability verbal scale.

This result is in congruence with the study done by Williams (1998) who tested the relationship between Young students' performance on neuropsychological measures of fluid cognition, and math achievement proved that training in increasing performance in mathematics would result in improvement of fluid cognitive skills and fluid IQ enhancement.

Table 4: Showing Comparative Mean Scores of the Reading and Math Groups on General Mental Ability -Non Verbal Scale

\begin{tabular}{|c|c|c|c|c|c|}
\hline Group & Pre/Post & Mean & SD & T TEST & P Value \\
\hline Experimental (R) & \multirow{2}{*}{ Pre } & 17.02 & 3.8 & \multirow{2}{*}{1.268} & \multirow{2}{*}{0.2} \\
\hline Control group $(\mathbf{R})$ & & 15.9 & 4.09 & & \\
\hline Experimental group (R) & \multirow{2}{*}{ Post } & 27.95 & 5.13 & \multirow{2}{*}{10.75} & \multirow{2}{*}{$0.0001 * *$} \\
\hline Control group $(\mathbf{R})$ & & 17.17 & 3.72 & & \\
\hline Experimental (M) & \multirow{2}{*}{ Pre } & 16 & 3.73 & \multirow{2}{*}{0.94} & \multirow{2}{*}{0.34} \\
\hline Control group $(\mathrm{M})$ & & 15.2 & 3.86 & & \\
\hline Experimental group $(\mathbf{M})$ & \multirow{2}{*}{ Post } & 25.22 & 4.21 & \multirow{2}{*}{10.23} & \multirow{2}{*}{$0.001 * *$} \\
\hline Control group (M) & & 16.72 & 3.14 & & \\
\hline
\end{tabular}

** $\mathrm{p}<0.01$ level of significance. $\mathrm{R}=$ Reading Disability group $\mathrm{M}=$ Math Disability group

Table 4 above shows the means, SDs and t values of non verbal scores of general mental ability between experimental groups and control groups (Reading and maths). On non verbal pre test experimental $\mathrm{R}$ group $\mathrm{m}=17.02$, $\mathrm{SD}=3.8$ whereas the mean score of the control group was $15.9 \& \mathrm{SD}=4.09$. When the pre test mean scores of the experimental and control group were compared, the ' $t$ ' value was 1.26 with $p<0.05$ indicated that the two groups showed no significant difference. In post test the mean score of experimental R was found to be 27.95 (SD=3.7) while the control group $\mathrm{R}$ mean was $17.17 \mathrm{SD}=3.72$. The ' $\mathrm{t}$ ' test revealed a significant difference between the experimental and control $\mathrm{R}$ group (the $\mathrm{t}$ value $=10.75 \mathrm{p}<0.01$ ). The high $\mathrm{t}$ value and significant $\mathrm{p}$ values indicate a high significant difference between 
the two groups, thus confirming the positive impact of cognitive intervention on the experimental (R).

When the pre test scores of experimental group (M) with mean 16\&SD 3.73 were compared with control group (M) mean $15.2 \& \mathrm{SD}=3.86$, the mean scores showed no significant difference between the two groups of students. The post intervention mean score of the experimental group was 25.2 with SD 4.21 control group mean score 16.72 (SD=3.14).The ' $t$ ' ratio between the two means was $t=10.23 \mathrm{p}$ value of 0.001 which indicate highly significant difference between the two groups. From the analysis, it could be concluded that cognitive intervention had a positive impact on both reading and maths experimental groups. This finding is in line with studies done by Posner, M.I., Roth Brit, M.K., \& Rueda, M.R., (2004) who reported that fluid cognition and general mental ability improved in experimental group children when compared with the control group.

Table 5: Shows Post Test Means of Experimental and Control Groups for Verbal Scale of Reading and Math Disability Students

\begin{tabular}{|c|c|c|c|c|c|c|c|c|c|c|}
\hline \multirow{2}{*}{ Groups } & \multicolumn{2}{|c|}{ Analogy } & \multicolumn{2}{|c|}{ Classification } & \multicolumn{2}{|c|}{ Number Series } & \multicolumn{2}{|c|}{ Reasoning } & \multicolumn{2}{|c|}{ Absurdities } \\
\hline & Mean & SD & Mean & SD & Mean & SD & Mean & SD & Mean & SD \\
\hline Experimental (R) & 7.8 & 4.02 & 6.17 & 1.04 & 6.8 & 1.3 & 7.2 & 0.86 & 6 & 0.9 \\
\hline Control (R) & 2.65 & 1.15 & 3.1 & 0.96 & 2.7 & 1.01 & 3.2 & 0.68 & 3.2 & 0.67 \\
\hline t value & \multicolumn{2}{|c|}{6.742} & \multicolumn{2}{|c|}{11.93} & \multicolumn{2}{|c|}{13.64} & \multicolumn{2}{|c|}{19.9} & \multicolumn{2}{|c|}{13.59} \\
\hline p value & \multicolumn{2}{|c|}{$0.001 * *$} & \multicolumn{2}{|c|}{$0.006 * *$} & \multicolumn{2}{|c|}{$0.0003 * *$} & \multicolumn{2}{|c|}{$0.001 * *$} & \multicolumn{2}{|c|}{$0.008 * *$} \\
\hline Experimental (M) & 5.6 & 0.8 & 6.3 & 0.8 & 6.8 & 1.1 & 7.22 & 0.82 & 6.72 & 0.99 \\
\hline Control (M) & 2.2 & 0.9 & 1.9 & 0.7 & 3.2 & 0.7 & 2.9 & 0.7 & 3.2 & 0.6 \\
\hline t values & \multicolumn{2}{|c|}{15.46} & \multicolumn{2}{|c|}{22.67} & \multicolumn{2}{|c|}{15.12} & \multicolumn{2}{|c|}{21.94} & \multicolumn{2}{|c|}{16.65} \\
\hline p value & \multicolumn{2}{|c|}{$0.01 * *$} & \multicolumn{2}{|c|}{$0.005 * *$} & \multicolumn{2}{|c|}{$0.003 * *$} & \multicolumn{2}{|c|}{$0.001 * *$} & \multicolumn{2}{|c|}{$0.019 * *$} \\
\hline
\end{tabular}

$* * \mathrm{p}<0.01$ level of significance $\mathrm{R}=$ Reading Disability group

M = Maths Disability group

The Table 5 depicts the findings of the post test means, standard deviations and t ratios of verbal skills of general mental ability test. The results of reading, the experimental group showed a mean score of 7.8 and SD of 4.02 in analogy dimension, whereas the mean of the control group was 2.65 and SD 1.15. The t test revealed a significant difference between the two groups of students with $t=6.74$ and $\mathrm{p}=0.001$. In the classification dimension of the verbal scale experimental group with a mean score of 6.17 and SD 1.04 showed a significant difference with $\mathrm{t}$ value of 11.93 ( $\mathrm{p}=0.006$ ) indicating significance control group whose mean was 3.1 and $\mathrm{SD}=0.96$. The mean score of the experimental $\mathrm{R}$ group in number series was 6.8 with SD 1.3 while the mean score of the control group $(\mathrm{M}=2.7$ and $\mathrm{SD}=1.01)$. When means of these two group were compared a significant difference was found with t value $=13.64$ and $\mathrm{p}$ value of 0.003 . In the reasoning dimension of the verbal cognitive skill, reading experimental group obtained a mean of 7.2 and SD 0.86 while the control group mean score was 3.2 and SD 0.68. A significant difference was found between these two groups of students with $\mathrm{t}=$ 19.9 and p value 0.001. Reading experimental group mean score in Absurdities was found to be 6 with 0.9 SD and the control group mean score was 3.2 with SD 0.67. Both the groups differed significantly on Absurdities with t value of 13.59 and p value 0.008. Reading experimental group obtained a high score in Analogy (7.8) and less in Absurdities (6).

The Math experimental group in the analogy dimension of verbal scale obtained a mean score of 5.6 and SD 2.2 while the control group mean score was 2.2 with SD 0.9. A significant difference was found between the two groups in analogy with $\mathrm{t}=15.4$ and $\mathrm{p}</=0.01$. In classification series the math experimental group mean score was 6.3 and SD 0.8 and control group mean score was found to be 1.9 and SD 0.7. The significant difference in classification was found between the experimental and control with $\mathrm{t}$ value $=22.6$ and a $\mathrm{p}$ value of 0.005 . The math experimental group obtained a 
mean score of 6.8 in number series with SD 1.1 and control group mean score was found to be 3.2, SD =0.7. When the mean scores of the two groups was compared with a significant difference was found with t value 15.12 and $\mathrm{p}$ value 0.03 . In the reasoning dimension of verbal scale the math experimental group mean score was 7.2 ( $\mathrm{SD}=2.9)$ while the control group mean score was 2.9 with $0.7 \mathrm{SD}$. A significant difference was found between the means of the two group comparison with $\mathrm{t}=21.9$ and the $\mathrm{p}$ value obtained is 0.001 . The experimental group in absurdities scored mean of $6.7 \&$ SD 0.9 . The control group scored 3.2 with 0.6 SD. When these means are compared the t value obtained was 16.65 and p value was 0.019 which indicate a significant difference between the two groups. The Math experimental group scored more in Reasoning dimension of verbal scale. The study concludes that cognitive intervention strategies helped the reading and math experimental group of students to score better in verbal scale than the control group students which didn't receive the intervention. Studies done by Nourbakhsh, S., Mansor, M., Maznah, B., Madon, Z.(2013) proved that cognitive intervention strategies improve verbal cognitive abilities among learning disabled children receive intervention which are in line with this study.

Table 6: Showing Comparison of Post Test Means, SDs, $T$ and 'P' Values of Experimental and Control Groups for Non Verbal Scale of General Mental Ability of Reading and Mathematics Disabled Students

\begin{tabular}{|c|c|c|c|c|c|c|c|c|c|c|}
\hline \multirow{2}{*}{ Groups } & \multicolumn{2}{|c|}{ Analogy } & \multicolumn{2}{|c|}{ Classification } & \multicolumn{2}{|c|}{$\begin{array}{c}\text { Number } \\
\text { Series }\end{array}$} & \multicolumn{2}{|c|}{ Reasoning } & \multicolumn{2}{|c|}{ Absurdities } \\
\hline & Mean & SD & Mean & SD & Mean & SD & Mean & SD & Mean & SD \\
\hline Experimental (R) & 7 & 1.02 & 5.8 & 0.9 & 5.3 & 1.1 & 5.6 & 0.9 & 5.5 & 0.7 \\
\hline Control (R) & 3.8 & 0.9 & 2.71 & 0.96 & 2.7 & 0.9 & 2.8 & 0.8 & 2.3 & 1.04 \\
\hline p value & \multicolumn{2}{|c|}{$0.001 * *$} & \multicolumn{2}{|c|}{$0.006^{* *}$} & \multicolumn{2}{|c|}{$0.0003^{* *}$} & \multicolumn{2}{|c|}{$0.001 * *$} & \multicolumn{2}{|c|}{$0.008^{* *}$} \\
\hline Experimental (M) & 6.7 & 0.9 & 5.8 & 0.9 & 5.7 & 0.7 & 5.7 & 1.3 & 7 & 1.04 \\
\hline Control (M) & 3.9 & 0.8 & 2.9 & 0.7 & 2.8 & 0.9 & 2.5 & 0.7 & 2.3 & 0.6 \\
\hline p value & \multicolumn{2}{|c|}{$0.01^{* *}$} & \multicolumn{2}{|c|}{$0.005^{* *}$} & \multicolumn{2}{|c|}{$0.003 * *$} & \multicolumn{2}{|c|}{$0.001 * *$} & \multicolumn{2}{|c|}{$0.019 * *$} \\
\hline
\end{tabular}

$* * \mathrm{p}<0.01$ level of significance $\mathrm{R}=$ Reading disability group $\mathrm{M}=$ Math disability group

The table 6 depicts the mean, SDs and t values of experimental and control group students for non verbal skills of reading and math disabled students. The reading experimental group in analogy series obtained a score of 7 and SD 1.02 and the control group mean score was 3.8 and SD 0.9. The $t$ test of two mean comparisons revealed $t$ value of 12.8 and $p=$ 0.001 which indicated a significant difference between the two group students. In the Classification dimension of non verbal skills the reading experimental group of students mean score was 5.8 with SD 0.9 and the control group mean was 2.7 with 0.9 SD. The $t$ test showed a significant difference between the two groups as the $t$ value obtained was 13.29 and $\mathrm{p}=0.006$. The experimental reading group mean score in number series was 5.3 and $\mathrm{SD}=1.1$ while the control group mean was 2.7 and $\mathrm{SD}=0.9$. When the two means obtained was compared $\mathrm{t}$ test revealed a significant difference between the two groups with $\mathrm{t}=9.98$ and $\mathrm{p}=0.0003$. In reasoning dimension the experimental group $\mathrm{R}$ scored $5.6(\mathrm{SD}=0.9)$ and the control group score mean was 2.8 with SD 0.8. The t test showed a significant difference between the experimental and control group of students as the $\mathrm{t}$ value obtained was 12.7 and $\mathrm{p}$ value was 0.001 . The mean score of reading experimental group in absurdities was 5.5 and $\mathrm{SD}=0.7$ while the control group mean score was 2.3 and $\mathrm{SD} 1.04$. When the two groups were compared using a t test value obtained was 13.98 and corresponding $\mathrm{p}$ value of 0.008 indicated a significant difference between them.

The math experimental group in analogy of non verbal skills obtained scores of 6.7 and $0.9 \mathrm{SD}$. The control group mean score was 3.9 and $\mathrm{SD}=0.8$. The $\mathrm{t}$ test showed a significant difference between the two groups as the $\mathrm{t}$ value was 12.7 and $\mathrm{p}=0,01$. In Classification the experimental group of students scored 5.8 and SD 0.9 while the control group scored 2.9 and SD 0.7. When the two means were compared using t test the values obtained were $t=13.9$ and $p=0.005$ which showed a 
significant difference between the two groups of students. The mean score in number series for the experimental group was $5.7(\mathrm{SD}=0.7)$ and for the control group was $2.8(\mathrm{SD}=0.9)$ was compared tvaue obtained was 13.3 and $\mathrm{p}=0.003$ which indicated a significant difference between the experimental and control group math disabled students. In reasoning dimension the two groups of math experimental and control showed a significant difference $(\mathrm{t}=11.8$ and $\mathrm{p}=0.001)$ when the mean score of experimental $(n=5.7$ and $S D=1.3)$ was compared with a mean score of control $(n=2.5$ and $S D=0.7)$. The math experimental group mean score in absurdities was 7 and SD 1.04. The control group mean was 2.3 and SD 0.6. When the two groups mean scores was compared the $\mathrm{t}$ value obtained 21.4 and $\mathrm{p}=0.001$ revealed a significant difference. These findings coincide with results obtained by Bryant, D.P., Brian, R., Russell,G., Melissa, M., (2008) who concluded that intervention (explicit and strategic) for students with mathematics difficulties holds promise for improving performance in number sense tasks, arithmetic combinations and quantitative reasoning tasks.

The study concludes that both reading and math experimental group of subjects performed better with mean scores greater than those of the control group. This is due to the effective cognitive intervention strategies which improved the skills of experimental groups.

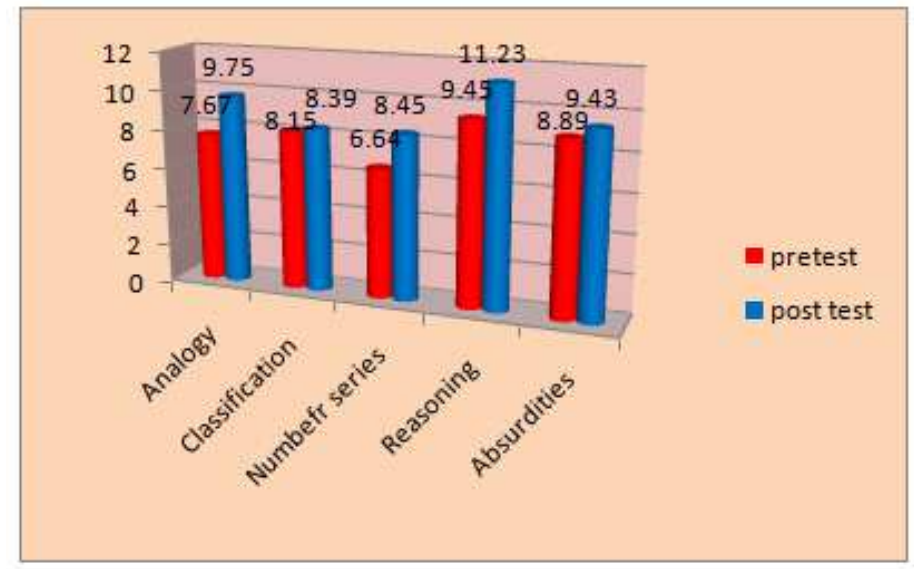

Figure 1: Mean Scores of Experimental Group Pre and Post Test General Mental Ability Sub Scales

Experimental I= Reading disabled group Experimental II= Mathematics disabled group Control Group I= Reading disabled group Control Group II= Mathematics disabled group

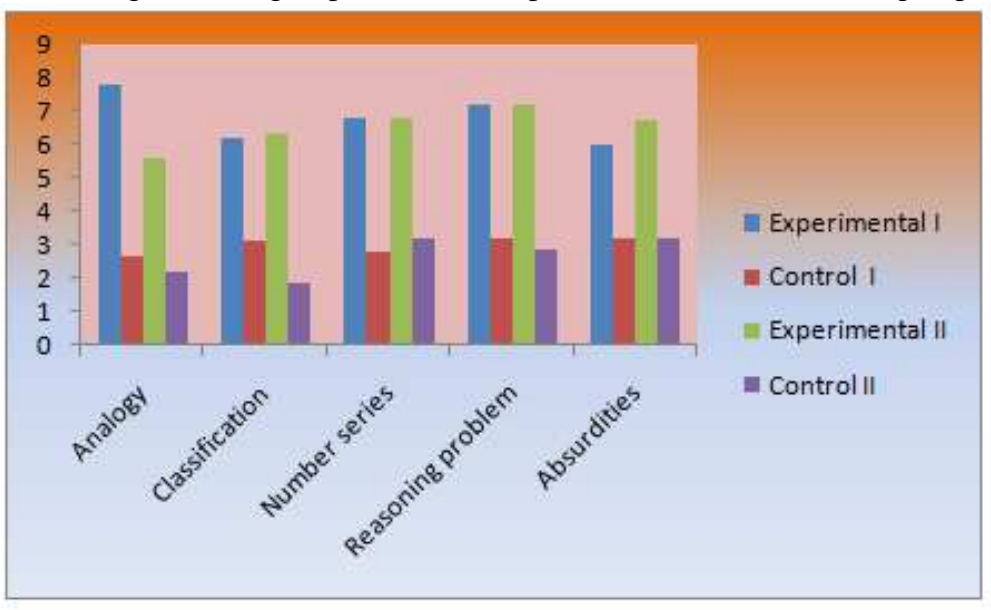

Figure 2: Mean Score Differences between Experimental and 


\section{Control Groups on Subscales of General Mental Ability}

\section{CONCLUSIONS}

Comprehensive programs of classroom-based cognitive intervention to improve reading comprehension or number competencies when implemented effectively, have a powerful and positive effect on the student's development of cognitive abilities.

\section{REFERENCES}

1. Vygotsky, L. (1978). Interaction Between. Learning and Development. In Gauvain \&. Cole (Eds) Readings on the Development of Children. New York: Scientific.

2. Ceci, S. (1991). How much does schooling influence general intelligence and its cognitive components? A reassessment of the evidence. Developmental Psychology, 27(5), 703 - 722.

3. Klingberg T, Forssberg H, Westerberg $H$ (2002b), Training of working memory in children with ADHD. J ClinExpNeuropsychol 24:781-791

4. Williams, W. M. (1998). Are we raising smarter children today? School-and home-related influences on IQ. In U. Neisser (Ed.), The rising curve: Long term gains in IQ and related measures (pp. 125 - 154). Washington, DC7 American Psychological Association.

5. Posner, M., \&Rothbart, M. (2004).Educating the human brain.In press.

6. Posner, M., Rothbart, M., Rueda, R. (2004, February).Developing self-regulation in preschool children. Paper presented at the annual meeting of the American Association for the Advancement of Science, Seattle Washington

7. Nourbakhsh, S., Mansor, M., Maznah, B., Madon, Z.(2013) The Effects of Multisensory Method and Cognitive Skills Training on Perceptual Performance and Reading Ability among Dyslexic Students.International Journal of Psychological Studies, 2013, Vol5, No2

8. Bryant, D. P., Bryant, B. R., Gersten, R., Scammacca, N., \& Chavez, M. M. (2008). Mathematics intervention for first-and second-grade students with mathematics difficulties: The effects of Tier 2 intervention delivered as booster lessons. Remedial and Special Education, 29, 20-32. 